Part of Journal of Research of the National Bureau of Standards, Volume 19, August 1937

\title{
PERMEABILITY OF ORGANIC POLYSULPHIDE RESINS TO HYDROGEN ${ }^{1}$
}

\author{
By Theron P. Sager
}

\begin{abstract}
The ability of films of organic materials to impede the passage of gases is of importance in connection with many of our modern products and particularly balloon and airship fabrics, where thin films and large surfaces are encountered. The tendency for hydrogen and helium to diffuse readily through rubber has been the incentive for the study of a large number of film-forming materials. Among these the product resulting from the reaction between dichloroethane and sodium polysulphide attracted particular interest since it not only exhibited a high impedance to hydrogen but possessed other desirable physical characteristics as well. A more comprehensive study indicates that other products, resulting from the general reaction between organic dihalides, having $-\mathrm{CH}_{2} \mathrm{Cl}$ terminals, and metallic polysulphides, have the same relatively low permeability to hydrogen. Data are presented which indicate that the lowest permeabilities are obtained with products containing four sulphur atoms in the primary molecule. Comparison with films of natural rubber show, that for both the disulphide and tetrasulphide derivatives, a much lower permeability is obtained with these products. The permeabilities of fabrics coated with both derivatives indicate the same relative behavior. Factors affecting the limitations of weights of coatings and the permeability to helium are discussed.
\end{abstract}

\section{CONTENTS}

Page

I. Introduction

III. Permeabilities of films unsupported by fabrics _. _

IV. Permeabilities of coated fabrics

V. Effect of pigmentation

VI. Permeability of helium

VII. Mechanism of permeation

VIII. References

\section{INTRODUCTION}

A characteristic of balloon and airship fabrics which is of prime importance is that they shall be gas-tight, or nearly so. The inherent tendency of hydrogen and of the more costly gas helium to diffuse through thin membranes of rubber provides the incentive for the study of the behavior of a large number of film-forming materials in a search for a more satisfactory material. Considering all of the requirements involved in this application, the permeability of the group of synthetic polymers which are characterized by elastic extensibility has been of particular interest.

\footnotetext{
1 Presented as part of the Symposium on Organic Plastics before the Division of Paint and Varnish Chemistry at the 93rd Meeting of the American Chemical Society, Chapel Hill, N. C., April 12 to $15,1937$.
} 
The general reaction between organic dihalides, having $-\mathrm{CH}_{2} \mathrm{Cl}$ terminals, and inorganic polysulphides has been shown to yield products which in many cases are characterized as rubber-like. Martin and Patrick $[3,4]^{2}$ have suggested that the structure of the polysulphide resins is that of long-chain polymers in which the radicals are connected through disulphide linkages and represented as: $-\mathrm{R}-\mathrm{S}-$ $\mathrm{S}-\mathrm{R}-\mathrm{S}-\mathrm{S}-\mathrm{R}-$. According to their hypothesis any additional sulphur in the material in excess of that required to provide the disulphide linkages is believed to be coordinately linked to the sulphur comprising the disulphide linkages. The structure is represented as

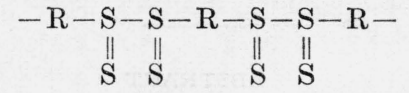

with the added possibility that the coordinately linked sulphur may be in a trans rather than a cis arrangement. It has been shown that the radical may be derived from ethylene or one of its homologs, or it may be obtained from a reactant containing an ether group, a sulphide group, or an unsaturated group. It is of interest particularly in connection with the present discussion that certain of these products exhibit elasticity, both when the amount of sulphur is confined to that representing the disulphide linkages and when the primary molecule contains sulphur in excess of these linkages.

What is often given as the specific example of the formation of this type of plastic is the product obtained when the reactants are dichloroethane and sodium polysulphide. Shortly after the addition of this material to the growing list of synthetic plastics, a compound containing this material was applied to a closely woven fabric by calendering. The weight of coating was $5.2 \mathrm{oz} / \mathrm{yd}^{2}\left(176 \mathrm{~g} / \mathrm{m}^{2}\right)$. The permeability to hydrogen of this fabric was found to be $0.014 \mathrm{ft}^{3} / \mathrm{yd}^{2}(0.5$ liter $/ \mathrm{m}^{2}$ ) per 24 hours. The low permeability of this material can be appreciated more fully when it is stated that a fabric coated with the same weight of a rubber compound would have a permeability of as much as 20 times this value.

There were, however, several objections to the use of the polyethylene polysulphide product for this purpose. This material cannot be dispersed in suitable solvents and does not therefore adapt itself easily to application in the form of a plurality of thin films to fabric. A somewhat less important objection is its distinctive and unpleasant odor, which made it undesirable for use on gas-cell fabric aboard an airship. With the extension of this general reaction to include other organic dihalides and the production of materials which are capable of being dispersed in solvents to form cements, their utility was greatly enhanced and their laboratory investigation rendered comparatively simple. The odor of these products is moreover much less offensive.

\section{EXPERIMENTAL METHOD}

'The materials were prepared in a manner similar to the preparation of rubber cements; the resins were masticated on a differential speed mill and the compounding ingredients were added on the mill. The compounds contained ten parts of zinc oxide and one-tenth to twotenths part of such accelerators as tetramethylthiuram disulphide and

2 Numbers in brackets refer to the references at the end of this paper. 
benzothiazyl disulphide. Thin cements were prepared by dispersing the compounds in beta-trichloroethane. In the preparation of films unsupported by fabric, the cements were applied to regenerated cellulose sheeting which had not been coated with any moisture-proofing composition [5]. After being cured in dry heat for 50 minutes at $130^{\circ}$ C $\left(268^{\circ} \mathrm{F}\right)$, the uncoated surface of the regenerated cellulose was moistened with water. The polysulphide films could then be removed without any appreciable deformation. In the preparation of coated fabrics, the cements were applied to closely woven balloon cloth by means of a small spreading machine. The curing conditions were the same as for the unsupported films.

The permeabilities were determined by means of a gas interferometer of the Rayleigh type. The apparatus and conditions of test have been previously described [1].

\section{PERMEABILITIES OF FILMS UNSUPPORTED BY FABRIC}

In table 1 are presented the permeabilities to hydrogen obtained with unsupported films of different thicknesses. The organic polysulphide products represent the disulphide and tetrasulphide derivatives obtained from the reaction between 2, $2^{\prime}$-dichloroethyl ether and sodium polysulphide. Values obtained with films of rubber of approximately corresponding thicknesses are included for comparison.

\section{TABLE 1.-Permeabilities to hydrogen of unsupported films}

DISULPHIDE DERIVATIVE

\begin{tabular}{|c|c|c|c|c|}
\hline \multicolumn{2}{|c|}{ Average thickness } & \multicolumn{2}{|c|}{ Permeability } & $\begin{array}{l}\text { Specific } \\
\text { permea- } \\
\text { bility }\end{array}$ \\
\hline $\begin{array}{l}\mathrm{cm} \\
0.030 \\
.025 \\
.017 \\
.015 \\
.011\end{array}$ & $\begin{array}{l}\text { in. } \\
0.012 \\
.010 \\
.007 \\
.006 \\
.004\end{array}$ & $\begin{array}{r}1 / \mathrm{m}^{2} / 24 \mathrm{hr} \\
0.6 \\
.8 \\
1.4 \\
1.5 \\
2.2\end{array}$ & $\begin{array}{r}\mathrm{ft}^{3} / \mathrm{yd}^{2} / 24 \mathrm{hr} \\
0.018 \\
.024 \\
.041 \\
.044 \\
.065\end{array}$ & $\begin{array}{l}12.5 \\
13.8 \\
16.2 \\
14.6 \\
16.8\end{array}$ \\
\hline \multicolumn{5}{|c|}{ TETRASULPHIDE DERIVATIVE } \\
\hline $\begin{array}{r}0.033 \\
.024 \\
.019 \\
.016 \\
.009\end{array}$ & $\begin{array}{r}0.013 \\
.010 \\
.008 \\
.006 \\
.004\end{array}$ & $\begin{array}{r}0.2 \\
.4 \\
.6 \\
.8 \\
1.2\end{array}$ & $\begin{array}{r}0.006 \\
.012 \\
.018 \\
.024 \\
.036\end{array}$ & $\begin{array}{l}4.5 \\
6.6 \\
7.9 \\
8.8 \\
7.5\end{array}$ \\
\hline \multicolumn{5}{|c|}{ RUBBER } \\
\hline $\begin{array}{r}0.030 \\
.025 \\
.018\end{array}$ & $\begin{array}{r}0.012 \\
.010 \\
.007\end{array}$ & $\begin{array}{l}10.0 \\
14.2 \\
20.0\end{array}$ & $\begin{array}{r}0.295 \\
.419 \\
.590\end{array}$ & $\begin{array}{l}208 \\
246 \\
250\end{array}$ \\
\hline
\end{tabular}

The results indicated sufficient uniformity to warrant the calculation of what may be called the specific permeability, or the volume of gas passing through a unit area of a material of unit thickness in unit time. This was calculated by means of the equation $P=V d / A t$, in which $P$ is the specific permeability, $V$ the volume of hydrogen in cubic centimeters, $d$ the thickness in centimeters, $A$ the area in square centimeters, and $t$ the time in minutes. 
The values for the specific permeability of rubber are in close agreement with those obtained by Kayser [2] and Edwards and Pickering [1]. The values obtained with both the disulphide and tetrasulphide derivatives are much lower than those with corresponding thicknesses of rubber, and those of the tetrasulphide product are consistently lower than those of the disulphide derivative.

While the specific permeabilities of the disulphide and tetrasulphide derivatives are of the same order of magnitude, they are not constant. This would appear to indicate that permeability in the case of these materials is not a linear function of the thickness. A possible explanation for this deviation is that the permeabilities were determined with a slight excess of pressure on the hydrogen side of the test specimen (30 $\mathrm{mm}$ of water), which, in the case of thin films, may have produced a small undeterminable reduction in thickness while under test.

\section{PERMEABILITIES OF COATED FABRICS}

It has been previously observed that the permeability of a given weight of rubber of definite area is greatly decreased when it is spread on a corresponding area of cloth [1.] It has also been noted that the thread count of the cloth exerts an influence [6]. The permeabilities of fabrics of different thread counts, coated with the same weight of rubber, become lower as the thread count increases. The values given in figure 1 represent the permeabilities obtained on a fabric coated with different weights of the two polysulphide resins which were employed in the determinations of the permeabilities of unsupported films. The cloth employed was that designated as $H H$ balloon cloth, a square-woven cotton fabric having a thread count of 120 in both directions, the average weight of a square yard being $2.05 \mathrm{oz}$.

The results indicate the same relative difference in the permeabilities of the two derivatives as was obtained in the examination of the unsupported films.

The effect of the supporting fabric upon the permeability is apparent when comparison is made with the values obtained for unsupported films given in table 1 . For example, a film of the tetrasulphide derivative having a thickness of $0.009 \mathrm{~cm}(0.004$ in.) weighs about 4.6 $\mathrm{oz} / \mathrm{yd}^{2}$. When unsupported by fabric, this film has a permeability of $0.035 \mathrm{ft}^{3} / \mathrm{yd}^{2} / 24 \mathrm{hr}$. If this same weight of material is applied to fabric, the permeability of the coated fabric will be, according to figure 1 , about $0.008 \mathrm{ft}^{3}$. Likewise, a film of the disulphide derivative $0.011 \mathrm{~cm}$ (0.004 in.) in thickness weighs about $4.2 \mathrm{oz} / \mathrm{yd}^{2}$ and has a permeability, when unsupported, of $0.064 \mathrm{ft}^{3}$. When applied to fabric the permeability of the coated fabric is about $0.035 \mathrm{ft}^{3}$.

The specific gravity of the compound containing the disulphide derivative is 1.426 and that containing the tetrasulphide derivative is 1.547. The covering power of these compounds is not, therefore, as high as that of a corresponding compound of rubber, the specific gravity of which would be about 0.995 . It is for this reason that, in the case of both derivatives, an abrupt increase in permeability occurs with decrease in weight of coating below about $2.6 \mathrm{oz}$. As the weight of material applied becomes less, it becomes increasingly difficult to cover the threads of the cloth uniformly with a continuous film. As the film becomes thinner it is probable that fibers of the fabric will protrude through the film, thus affording channels for leakage. 
That the permeabilities become practically constant within the range shown in figure 1 would appear to be explainable on the basis of the difference in the permeabilities of films attached to fabric and those which are unsupported. Within the range shown in figure 1 the permeability of the impregnated fabric and the thin film overlying it, represented by a weight of coating of about $2.8 \mathrm{oz} / \mathrm{yd}^{2}$, is apparently the controlling factor in the behavior of fabrics carrying higher weights of

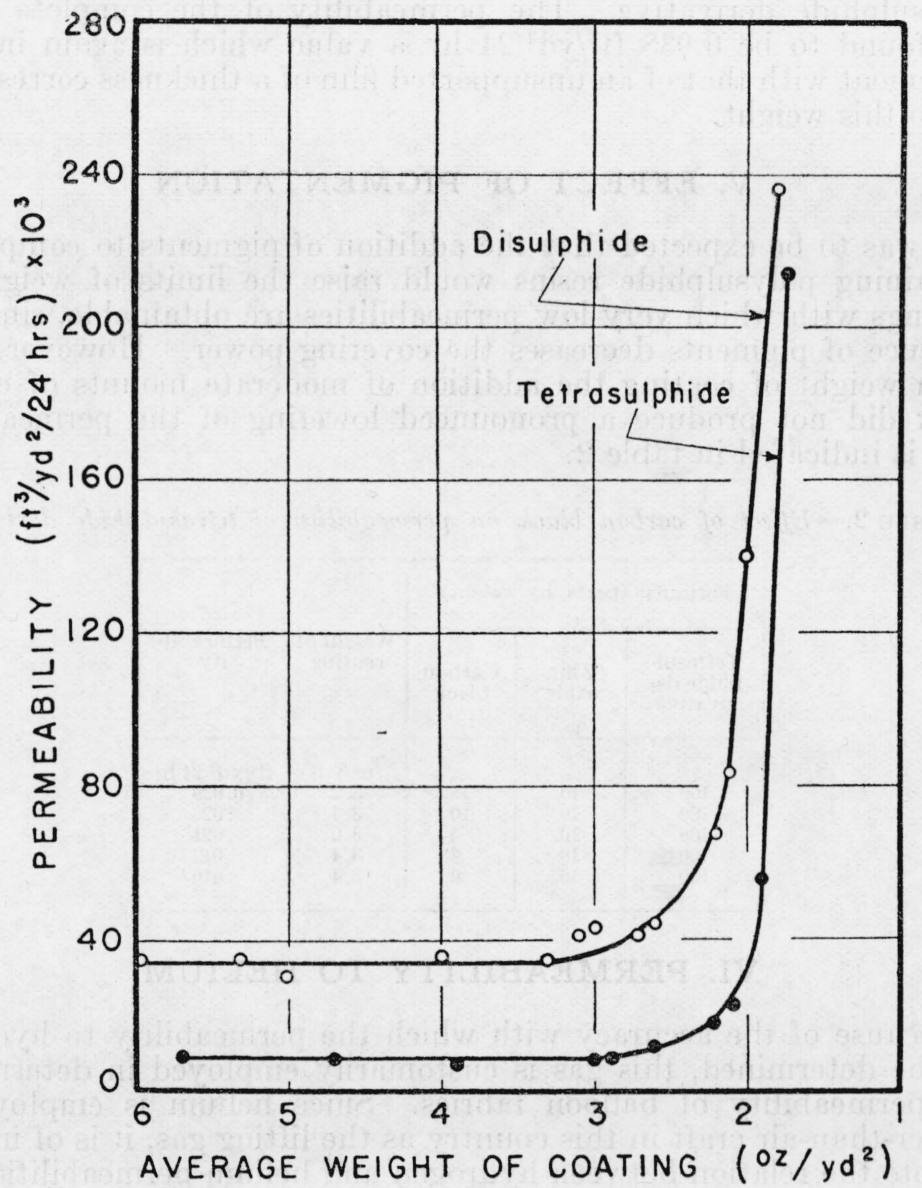

Figure 1.-Permeabilities of coated fabrics.

coatings. In accordance with this view the permeability of a coated fabric would be lowered further only when the thickness of the overlying film became sufficiently great as to have a permeability lower than that of the raw fabric, plus $2.8 \mathrm{oz}$ of coating. A fabric was prepared on which the total weight of coating was the equivalent of 15.5 $\mathrm{oz} / \mathrm{yd}^{2}$. The permeability of this fabric proved to be $0.003 \mathrm{ft}^{3} / \mathrm{yd}^{2} / 24$ hr, a value considerably lower than those in the practically constant range in figure 1 . The amount of overlying film in excess of the 2.8 $\mathrm{oz} / \mathrm{yd}^{2}$, representing the minimum constant value, was $12.7 \mathrm{oz}$, which corresponds approximately to a thickness of $0.029 \mathrm{~cm}$. Comparison 
of the permeability obtained with this fabric with that of an unsupported film of about this same thickness indicates fairly close agreement. The behavior of a resin film overlying a base fabric coated with rubber is also explainable on this basis. The weight of rubber applied to the raw fabric was about $0.6 \mathrm{oz} / \mathrm{yd}^{2}$. The permeability of a fabric coated with this weight of rubber is so high as to be negligible in its impedance value. The rubberized fabric was now coated with $4.6 \mathrm{oz} / \mathrm{yd}^{2}$ of the tetrasulphide derivative. The permeability of the complete fabric was found to be $0.038 \mathrm{ft}^{3} / \mathrm{yd}^{2} / 24 \mathrm{hr}$, a value which is again in close agreement with that of an unsupported film of a thickness corresponding to this weight.

\section{EFFECT OF PIGMENTATION}

It was to be expected that the addition of pigments to compounds containing polysulphide resins would raise the limits of weights of coatings with which very low permeabilities are obtainable, since the presence of pigments decreases the covering power. However, for a given weight of coating the addition of moderate mounts of carbon black did not produce a pronounced lowering of the permeability. This is indicated in table 2 .

TABLE 2.-Effect of carbon black on permeability of tetrasulphide derivative

\begin{tabular}{|c|c|c|c|c|}
\hline \multicolumn{3}{|c|}{ Formulas (parts, by weight) } & \multirow{2}{*}{$\begin{array}{l}\text { Weight of } \\
\text { coating }\end{array}$} & \multirow[b]{2}{*}{$\underset{\text { ity }}{\text { Permeabil- }}$} \\
\hline $\begin{array}{l}\text { Tetrasul- } \\
\text { phide de- } \\
\text { rivative }\end{array}$ & $\begin{array}{l}\text { Zinc } \\
\text { oxide }\end{array}$ & $\begin{array}{c}\text { Carbon } \\
\text { black }\end{array}$ & & \\
\hline $\begin{array}{l}100 \\
100 \\
100 \\
100 \\
100\end{array}$ & $\begin{array}{l}10 \\
10 \\
10 \\
10 \\
10\end{array}$ & $\begin{array}{r}15 \\
10 \\
5 \\
2 \\
0\end{array}$ & $\begin{array}{c}\mathrm{oz} / \mathrm{yd} \mathrm{d}^{2} \\
3.2 \\
3.4 \\
3.0 \\
3.4 \\
3.4\end{array}$ & $\begin{array}{c}\mathrm{ft}^{3} / \mathrm{yd}^{2} / 24 \mathrm{hr} \\
0.029 \\
.023 \\
.021 \\
.012 \\
.010\end{array}$ \\
\hline
\end{tabular}

\section{PERMEABILITY TO HELIUM}

Because of the accuracy with which the permeability to hydrogen can be determined, this gas is customarily employed in determining the permeability of balloon fabrics. Since helium is employed in lighter-than-air craft in this country as the lifting gas, it is of interest to note the relation between hydrogen and helium permeabilities of a polysulphide resin. A few measurements made on fabrics coated with different weights of coatings on fabric are given in table 3 . The average ratio is in close agreement with that found previously for rubber [1]. 
TABLE 3.-Permeabilities of tetrasulphide derivative to hydrogen and helium

\begin{tabular}{|c|c|c|c|}
\hline & \multicolumn{3}{|c|}{ Permeability $\left(\mathrm{ft}^{3} / \mathrm{yd}^{2} / 24 \mathrm{hr}\right)$} \\
\hline & Helium & Hydrogen & $\begin{array}{l}\text { Ratio heli- } \\
\text { um to } \\
\text { hydrogen }\end{array}$ \\
\hline \multirow[b]{2}{*}{ Average ratio... } & $\begin{array}{r}0.006 \\
.011 \\
.014 \\
.009\end{array}$ & $\begin{array}{r}0.009 \\
.017 \\
.023 \\
.013\end{array}$ & $\begin{array}{l}0.66 \\
.64 \\
.60 \\
.66\end{array}$ \\
\hline & & - & 0.64 \\
\hline
\end{tabular}

\section{MECHANISM OF PERMEATION}

In a report which is largely concerned with the practical application of a material the nature of the data does not warrant definite conclusions regarding the mechanism of permeation. It is possible that the passage of a gas through a material may be simply filtration through intermolecular spacings or, in highly permeable substances, an actual porosity, or it may take place by a process of adsorption of the gas on the surface, followed by diffusion through the material. Under practical conditions, particularly with the heterogeneous compositions widely employed, both mechanisms may function. The behavior of the organic polysulphide resins may perhaps be explainable with either. In these resins the sulphur atoms are enormously large compared to the other constituents of the molecule. They are in effect linear polymers of sulphur atoms. From the viewpoint of simple mechanical phenomena the intermolecular spacings of substances containing such large amounts of sulphur must be small and a high degree of impedance might be anticipated. The lower permeability of the derivative containing the greater amount of sulphur might be attributed to a greater structural density in this substance. On the other hand, these materials would be expected to be inert compared to a material such as rubber, and hence would offer much less solvent action toward hydrogen. Concerning the relative behavior of the disulphide and tetrasulphide derivatives, it is to be expected that as the ratio of the sulphur atoms to the remainder of the molecule is altered changes in solubility relationships would result which would be reflected in the relative permeabilities of these substances.

The information reported herein was obtained in the course of an investigation conducted for the Bureau of Aeronautics, United States Navy Department. The interest of this organization and particularly that of Commander Garland Fulton is gratefully acknowledged.

\section{REFERENCES}

[1] J. D. Edwards and S. F. Pickering, BS Tech. Pap. 11 (1918) T113; BS Sci. Pap. 16, 327-362 (1920), S387.

[2] H. Kayser, Wied. Ann. 43, 544 (1891).

[3] S. M. Martin, Jr., and J. C. Patrick, Ind. Eng. Chem. 28, 1144-1149 (1936).

[4] J. C. Patrick, Trans. Faraday Soc. 32, no. 177, pt. 1, 347-357 (1936); Rubber Chem. Tech. 9, 373-382 (1936).

[5] T. P. Sager, Ind. Eng. Chem., Anal. Ed., 9, 156 (1937).

[6] T. P. Sager, J. Research NBS, 13, 879-885 (1934); RP750.

Washington, March 20, 1937. 